\title{
Exemestane/Lapatinib/Trastuzumab Regimen
}

National Cancer Institute

\section{Source}

National Cancer Institute. Exemestane/Lapatinib/Trastuzumab Regimen. NCI Thesaurus. Code C156303.

A chemotherapy regimen consisting of exemestane, lapatinib, and trastuzumab that may be used in the treatment of premenopausal women with hormone receptor-positive, human epidermal growth factor receptor 2 (HER2; HER-2; ERBB2)-positive recurrent or metastatic breast cancer. 